\title{
Chorioretinitis sclopetaria
}

\author{
Coriorretinite esclopetária
}

Isaac Carvalho de Oliveira Ramos ${ }^{1,2}$, Diogo Carvalho Macedo dos Santos ${ }^{1,2}$, Itamar Soares ${ }^{1,2}$, Vitor Cerqueira ${ }^{3}$

\begin{abstract}
The objective of this study is to report a case of ocular trauma by gunshot bullet, which struck and lodged in the orbit, developing chorioretinitis sclopetaria. We also addressed the pathophysiological mechanism, the main clinical findings and laboratory tests, and treatment options. The characteristic of this case enhances the importance of a multidisciplinary approach in the ocular trauma.

Keywords: Chorioretinitis/physiopathology; Chorioretinitis/therapy; Gunshot wounds; Penetrating eye injuries; Choroid/injuries; Rupture; Case reports
\end{abstract}

\section{RESUMO}

O objetivo deste trabalho é relatar um caso de trauma ocular por projétil de arma de fogo, que atingiu e se alojou na cavidade orbitária, desenvolvendo coriorretinite esclopetária. Foram abordados o mecanismo fisiopatológico, os principais achados clínicos e de exames complementares, além das opções de tratamento. As características do caso relatado reforçam a importância de uma abordagem multidisciplinar no trauma ocular.

Descritores: Coriorretinite/fisiopatologia; Coriorretinite/terapia; Ferimentos por arma de fogo; Ferimentos oculares penetrantes; Coroide/lesões; Ruptura; Relatos de casos

\footnotetext{
${ }^{1}$ Ophthalmologist at Hospital Nossa Senhora da Saúde - Gamboa, Rio de Janeiro - RJ, Brazil.

${ }^{2}$ Ophthalmologist at Hospital Municipal Souza Aguiar - Rio de Janeiro - RJ, Brazil.

${ }^{3}$ Masters in Ophthalmology, Federal University of Rio de Janeiro - UFRJ, Brazil; Professor at Estacio de Sá University - UNESA, Rio de Janeiro - RJ, Brazil; Ophthalmologist at Federal State Public Servant Hospital - HFSE, Rio de Janeiro - RJ, Brazil.
}

Study conducted at the Municipal Hospital Souza Aguiar, Rio de Janeiro - RJ, Brazil, and Hospital Nossa Senhora da Saúde - Gamboa, Rio de Janeiro - RJ, Brazil.

Os autores declaram não haver conflitos de interesse

Received for publication 09/07/2012 - Accepted for publication 15/04/2013 


\section{INTRODUCTION}

C horioretinitis sclopetaria is the term used to characterize an eye injury in which a firearm projectile (FAP) passes nearby the globe without perforating it, causing damage to the retina and choroid ${ }^{(1-15)}$. It was first described in 1901 by Goldzieher $^{(3,6,14,15)}$, but Kempster et al. mention Graefe as first reporting it in $1954^{(1)}$. This syndrome has received a variety of names which include proliferative chorioretinitis, proliferative plastic chorioretinitis and proliferative Lagrange chorioretinitis ${ }^{(14,15)}$.

The pathophysiological mechanism of the injury is caused by the energy release resulting from the high speed of the projectile when reaching the orbital cavity and passing close to the eyeball in its path ${ }^{(1-3,5,5,13-15)}$. Although there is no perforation, there is direct damage to the retina and/or choroid, or immediately adjacent to that path, generally parallel to the ora serrata. Indirect injury may be due to kickback mechanism, i.e., the shock waves propagate through the eyeball until reaching the posterior pole. Choroidal ruptures by kickback are generally concentric, vertical, and unique to the optic nerve, and can seriously compromise the macula ${ }^{(14,16-20)}$. In cases of multiple lesions, they are often parallel with the largest one being central and the smallest one peripheral. A compression mechanism (Commotio retinae) may also be involved, leading to Berlin edema $^{(21-27)}$.

Changes in motility, either by restriction or by direct injury of the extraocular muscles, may be present. The involvement of visual acuity is variable because it depends on the location and the extent of the injury. In the anterior segment, pupillary and photo-motor reflection changes may be present, and the intraocular pressure (IOP) can be altered as a result of ocular inflammation.

Although classically associated to FAPs, quite similar siuations have been described with compressed air projectiles and even with fishing equipment ${ }^{(6)}$.

The objective of this study is to report a case of chorioretinitis sclopetaria attended the emergency service of the Municipal Hospital Souza Aguiar (HMSA), and with ambulatory follow-up at Hospital Nossa Senhora da Saúde - Gamboa. The pathophysiological mechanism, the main clinical findings, possible complications and the treatment options will be discussed.

\section{Case RePort}

A 35 year old man, brown, was admitted tat the emergency service of HMSA on August 19, 2010, stating "gunshot in the right eye and blurred vision" two hours before in a robbery. The ectoscopy showed hematoma and bi-eyelid edema, besides contusion measuring a centimeter in the lower eyelid. Motility was preserved and the uncorrected visual acuity (VA) was 20/200 (RE) and 20/ 20 (LE). Biomicroscopy showed intact eyeball, conjunctival hyperemia, intense subconjunctival hemorrhage, transparent cornea, anterior chamber formed and wide, photo-reactive pupil and transparent lens. The IOP measurement with Goldmann applanation tonometry (GAT) was $13 \mathrm{mmHg}$ both eyes.

We requested a CT scan of skull and orbit, showing that the central nervous system was preserved and the presence of FAP in the right orbit cavity located below (Figure 1). The opinion of a neurologist was requested, which said it was normal, and along with the BMF the procedure was hospitalization for monitoring. The patient condition progressed to side abscess and subsequent restriction of adduction. The eye fundus showed important rupture of choroid, mild retinal whitening and discrete macular edema with cherry aspect, showing the Berlin edema. He then underwent surgery with a multidisciplinary approach (ophthalmology and BMF) to drain the abscess. It progressed to inert FAP in the inferior orbital cavity post surgery, and the patient was discharged for ambulatory follow-up.

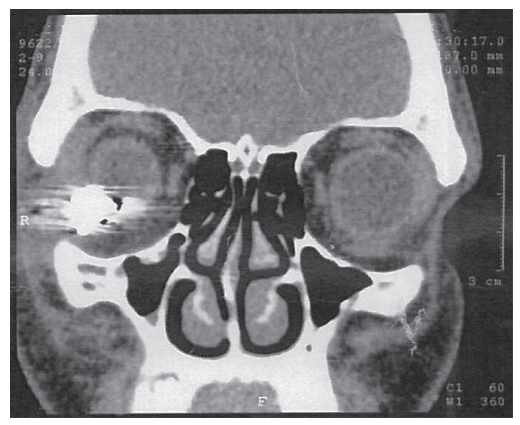

Figure 1. Computed tomography of skull and orbit, showing the central nervous system preserved and the presence of a FAP in the right orbit located inferiorly.

Four weeks after the trauma the patient went to inspection with right dystopia and reflection of Hirshberg and normal pupils. He reported mild pain and diplopia to abduction in the RE. The corrected visual acuity was 20/100, and he had no changes in biomicroscopy. The IOP was 7 and $11 \mathrm{mmHg}$ in the RE and LE, respectively. Retinotopy showed an important lower vitreous hemorrhage; subretinal hemorrhage and choroidal rupture in the periphery of the retina; as well as peri-macular (temporal) choroidal rupture concentric with the optic nerve. Said findings were confirmed by retinography and ecography (Figures 2 and $3)$. The procedure was expectant and the patient was followed up monthly with VA and GAT measurements, retinal mapping and visual field exams. He showed an improvement of the dystopia and moderate absorption of the vitreous hemorrhage, evolving to visual acuity of 20/40 and exam of macular acuity potential of 20/30 partial. He was stable for 18 months, with a small visual field defect in the nasal region (Figure 4) consistent with the topography of the peri-macular lesion. Optical coherence

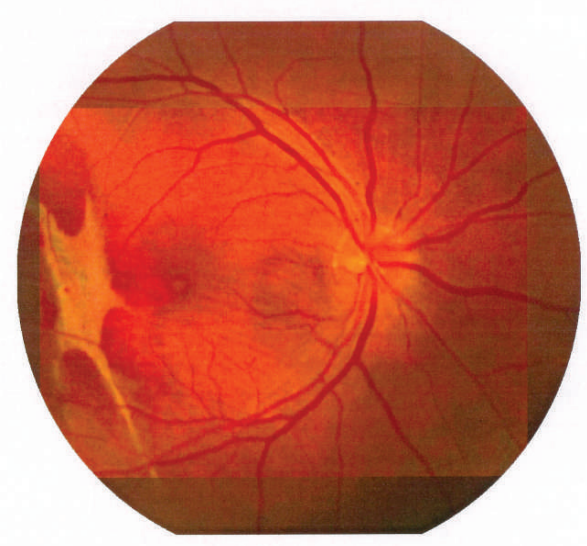

Figure 2. Simple retinography of the right eye showing choroidal rupture temporally reaching the macula and saving the foveal region. 


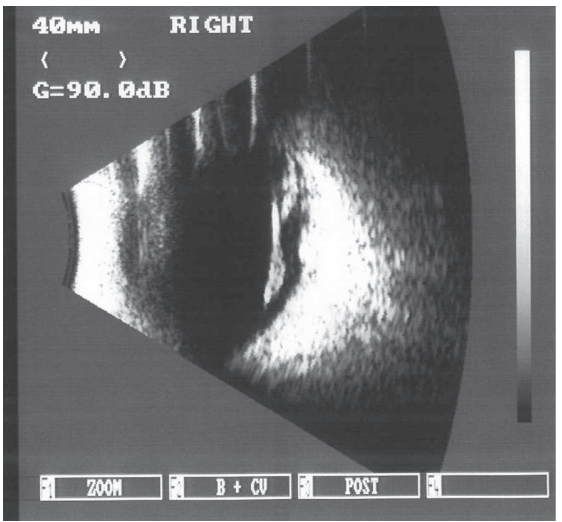

Figure 3. Eye ultrasonography of the right eye showing the lower vitreous hemorrhage.

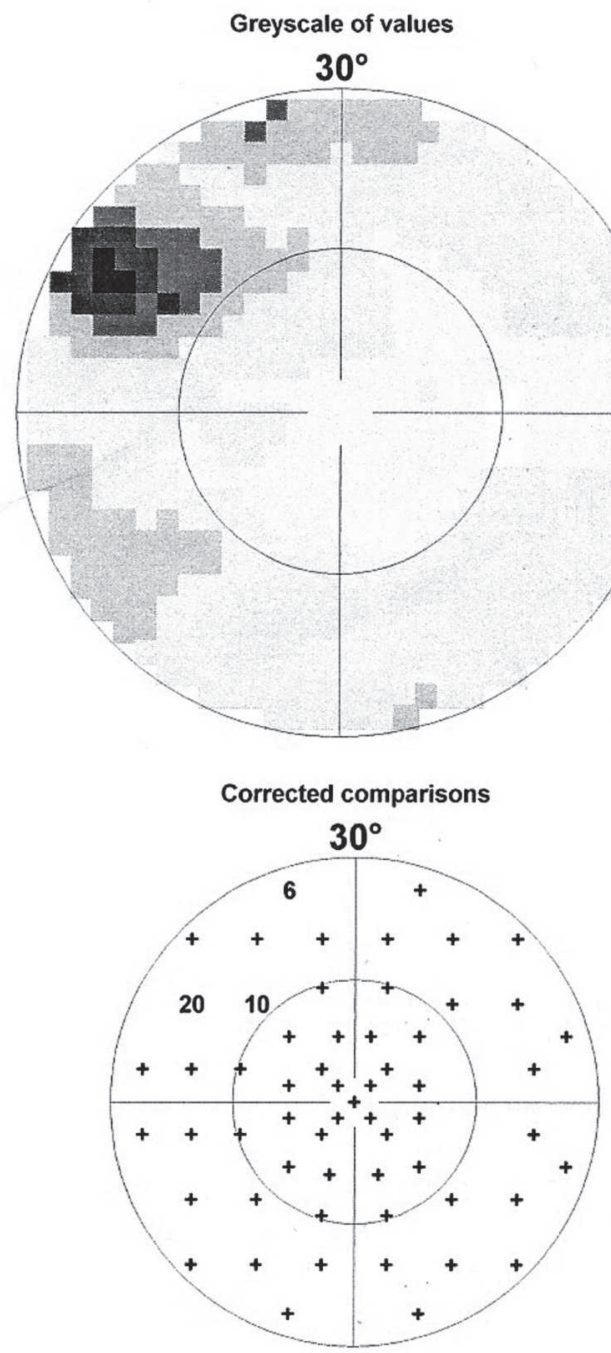

Figure 4. Computerized visual field of the right eye showing a defect of the superior nasal visual field consistent with the topography of the injury.

tomography showed no edema in the posterior pole, but it is noticed an expected disorder of the retinal pigment epithelium cells in the damaged area (Figure 5). The patient is still under follow-up every six months, undergoing the routine exams already mentioned, in addition to the fluorescein angioretinography in order to assess the possible onset of neovascularization.

\section{Discussion}

The chorioretinitis sclopetaria was introduced in the literature by Goldzieher in Germany in $1901^{(3,6,14,15)}$, and refers to the retinal and choroidal lesions secondary to a trauma by FAP passing adjacent to the eyeball. Although there is no perforation, ruptures
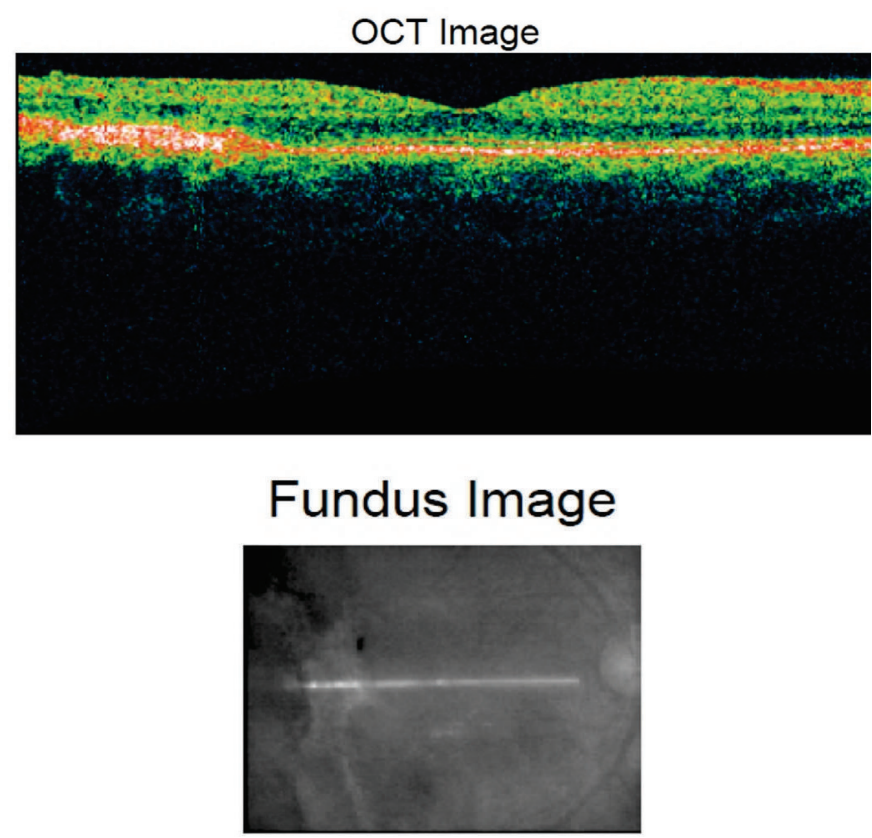

T

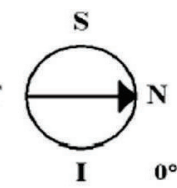

Figure 5. Optical coherence tomography (OCT) of the right eye showing the disorder of the retinal pigment epithelium near the macula.

in the retina and choroid, as well as macular edema may be present and seriously impair the visual acuity ${ }^{(1-15)}$.

The multidisciplinary approach should always be considered in cases of ocular trauma. In this report, the patient had no injury of the extrinsic muscles, but it progressed with limitation of adduction by restriction subsequent to the formation of lateral abscess. The procedure adopted along with neurosurgery and oral and maxillofacial surgery was the surgical drainage of the abscess, which was successfully performed.

Computed tomography showed no optic nerve lesion, but this is a condition that may occur in part or in its entirety, leading to significant losses of visual field and amaurosis ${ }^{(7)}$.

In the acute phase of chorioretinitis sclopetaria, hemorrhages (vitreous, retinal and/or subretinal), and choroidal and retinal ruptures can be seen, besides retinal edema ${ }^{(3,15)}$. These findings were observed in our patient with the choroidal rupture, 
partially reaching the macular region and consequently permanently impairing the visual field. It is known that the choroid ruptures are associated with blunt trauma, either by direct or indirect mechanism ${ }^{(19,28-32)}$. Retinal and macula whitening with a cherry aspect (Berlin edema) have also been reported after eye injuries, a condition that is known as commotio retinae $^{(21-27)}$. Both can appear in chorioretinitis sclopetaria, as it also has a blunt component in its pathophysiology. In our case the edema was lightly to moderately present in the acute phase, and was regressing with parallel recovery of the visual acuity $(20 / 200$ to $20 / 40)$.

In eyes with chorioretinitis sclopetaria, it is tempting to intervene in some way because of the often scary size and the posterior location of the retinal rupture. However, the retina rarely desplaces in this situation, presumably because of an inflammation in the edges of the necrotic retina leading to a firm chorioretinal adhesion. Furthermore, it is believed that the retina and choroid are retracted as a single unit, with the posterior hyaloid remaining intact from rupture, preventing the entrance of the vitreous into the subretinal space ${ }^{(1,3,15)}$. If a retinal detachment occurs, it is usually at another site. Therefore, it is not necessary to perform prophylactic cryopexy or photocoagulation.

The late complication of the chorioretinitis sclopetaria is the same choroidal rupture in another situation, i.e., the possibility of developing neovascularization from the choroid and fibrovascular proliferation. This occurs in 25 to $50 \%$ after one year of the choroid ruptures ${ }^{(6,28-32)}$. Our patient is currently in the 18th month after injury, and is being closely monitored with fluorescein angioretinography, getting normal results so far.

It is important to mention that there is no exact model in the chorioretinitis sclopetaria injuries; the extent of the injury will vary according to the type of gun, projectile caliber, distance from the weapon to the target, pathway and interaction with various ocular structures that have varied tissue resistances. It can be found from small peripheral retinal injuries to optic nerve avulsion. Supplementary exams are needed to elucidate the diagnosis. The tomography of skull and orbit is enlightening to locate the projectile, in addition to assess the impairment level of the central nervous system. In ambulatory level follow-up is done with retina mappings, fluorescein angioretinography, ecography, optical coherence tomography (OCT) and visual field. Following the same reasoning, the treatment and the visual prognosis are variable and depend on the extent and location of the lesion.

\section{Conclusion}

This paper aims at alerting ophthalmologists so that whenever treating a patient with ocular trauma by FAP they are aware of the diagnosis of chorioretinitis sclopetaria. Due to the multidisciplinarity of the trauma, it is of great importance the the assessment is made along other medical specialties.

\section{ReferenCeS}

1. Ahmadabadi MN,Karkhaneh R, Roohipoor R,Tabatabai A,Alimardani A. Clinical presentation and outcome of chorioretinitis sclopetaria: a case series study. Injury. 2010;41(1):82-5.
2. Beatty S, Smyth K, Au Eong KG,Lavin MJ. Chorioretinitis sclopetaria. Injury. 2000;31(1):55-60.

3. Dubovy SR, Guyton DL, Green WR. Clinicopathologic correlation of chorioretinitis sclopetaria. Retina. 1997;17(6):510-20.

4. Germani L, Viale C. [Unusual ocular traumatic syndrome: chorioretinitis sclopetaria]. Minerva Oftalmol. 1970;12(3):100-2. Italian.

5. Hart JC, Natsikos VE, Raistrick ER, Doran RM. Chorioretinitis sclopetaria. Trans Ophthalmol Soc U K. 1980;100(Pt 2):276-81.

6. Katsumata S, Takahashi J,Tamai M. Chorioretinitis sclopetaria caused by fishing line sinker. Jpn J Ophthalmol. 1984;28(1):69-74.

7. Mohammadpour M, Soheilian M. Concomitant optic nerve transection and chorioretinitis sclopetaria. BMC Ophthalmol. 2005;5:29.

8. Otto CS, Nixon KL, Mazzoli RA, Raymond WR 4th, Ainbinder DJ, Hansen EA, et al. Chorioretinitis sclopetaria from BB ex memoria. Ophthalmic Surg Lasers. 2001;32(2):152-5.

9. Pérez-Carro G, Junceda-Moreno C. [Dual cause of blindness: chorioretinitis sclopetaria and homonymous hemianopsia]. Arch Soc Esp Oftalmol. 2006;81(2):119-22. Spanish.

10. Perry HD, Rahn EK. Chorioretinitis sclopetaria: choroidal and retinal concussion injury from a bullet. Arch Ophthalmol. 1977;95(2):328-9.

11. Ahmadabadi MN, Rajabi MT. Evolution of retinitis sclopetaria after blunt trauma: comment. Clin Experiment Ophthalmol. 2010;38(7):7378; author reply 8. Comment on Clin Experiment Ophthalmol. 2009;37(9):896-7.

12. Georgalas I, Koutsandrea C, Papaconstantinou D, Kampougeris G, Ladas I. Evolution of retinitis sclopetaria after blunt trauma. Clin Experiment Ophthalmol. 2009;37(9):896-7. Comment in Clin Experiment Ophthalmol. 2010;38(7):737-8; author reply 738.

13. Maguluri S, Hartnett ME. Radial choroidal ruptures in sclopetaria. J Am Coll Surg. 2003;197(4):689-90.

14. Martin DF,Awh CC, McCuen BW 2nd, Jaffe GJ,Slott JH, Machemer R. Treatment and pathogenesis of traumatic chorioretinal rupture (sclopetaria). Am J Ophthalmol. 1994;117(2):190-200.

15. Richards RD, West CE, Meisels AA. Chorioretinitis sclopetaria. Am J Ophthalmol. 1968;66(5):852-60.

16. Kempster RC, Green WR, Finkelstein D. Choroidal rupture. Clinicopathologic correlation of an unusual case. Retina. 1996;16(1):57-63. Retina. 1996;16(1):57-63.

17. Grosso A, Panico C. Surgical management of sclopetaria associated with macular hole in a young patient: long term results. Eye (Lond). 2009;23(9):1875-6.

18. Kunjukunju N, Navarro A, Oliver S, Olson J, Patel C, Garcia G, et al. Bilateral macular hole formation secondary to sclopetaria caused by shockwaves transmitted by a posterior vector: case report. BMC Ophthalmol. 2010;10:6.

19. Neame H. Multiple ruptures of choroid with retention of good vision. Br J Ophthalmol. 1940;24(8):399-400.

20. Williams DF, Mieler WF, Williams GA. Posterior segment manifestations of ocular trauma. Retina. 1990;10 Suppl 1:S35-44. Review.

21. Itakura H, Kishi S. Restored photoreceptor outer segment in commotio retinae. Ophthalmic Surg Lasers Imaging. 2011;42 Online:e29-31.

22. Liem AT, Keunen JE, van Norren D. Reversible cone photoreceptor injury in commotio retinae of the macula. Retina. 1995;15(1):58-61.

23. Morita C, Preti RC, Ferraz DA, Maia Júnior OO, Takahashi WY. Tomografia de coerência óptica na commotio retinae: relato de caso. Arq Bras Oftalmol. 2009;72(4):533-6.

24. Park JY,Nam WH, Kim SH, Jang SY, Ohn YH, Park TK. Evaluation of the central macula in commotio retinae not associated with other types of traumatic retinopathy. Korean J Ophthalmol. 2011;25(4):262-7. 
25. Souza-Santos F, Lavinsky D, Moraes NS, Castro AR, Cardillo JA, Farah ME. Spectral-domain optical coherence tomography in patients with commotio retinae. Retina. 2012;32(4):711-8.

26. Umeed S, Shafquat S. Commotio-retinae and central retinal artery occlusion after blunt ocular trauma. Eye (Lond). 2004;18(3):333-4.

27. Kohno T, Ishibashi $\mathrm{T}$, Inomata $\mathrm{H}$, Ikui H, Taniguchi Y. Experimental macular edema of commotio retinae: preliminary report. Jpn J Ophthalmol. 1983;27(1):149-56.

28. Artunay O, Rasier R, Yuzbasioglu E, Sengül A, Bahcecioglu H. Intravitreal bevacizumab injection in patients with choroidal neovascularization due to choroid rupture after blunt-head trauma. Int Ophthalmol. 2009;29(4):289-91.

29. Mennel S, Hausmann N, Meyer CH, Peter S. Photodynamic therapy and indocyanine green guided feeder vessel photocoagulation of choroidal neovascularization secondary to choroid rupture after blunt trauma. Graefes Arch Clin Exp Ophthalmol. 2005;243(1):68-71.
30. Oya Y, Yoshizawa T, Aoki S, Kurihara A, Abe H. [A case of choroidal rupture due to blunt ocular trauma healed with proliferative tissue protruding into the vitreous cavity]. Nihon Ganka Gakkai Zasshi. 2002;106(11):721-7. Japanese.

31. Takahashi M, Kinoshita S, Saito W, Kase M, Ishida S. Choroidal neovascularization in a patient with blunt trauma-caused traumatic retinopathy without choroidal rupture. Graefes Arch Clin Exp Ophthalmol. 2011;249(1):137-40.

32. Wyszynski RE, Grossniklaus HE, Frank KE. Indirect choroidal rupture secondary to blunt ocular trauma. A review of eight eyes. Retina. 1988;8(4):237-43.

\section{Corresponding author:}

Isaac Carvalho de Oliveira Ramos. Rua General Goes Monteiro, number 8, Block E, Apt.: 1803, Botafogo, ZIP Code: 22290-030, Rio de Janeiro - RJ, Brazil

E-mail: isaacramos_@hotmail.com 